\title{
Espaços de Politização e Processos de Engajamento em Sergipe*
}

Ernesto Seidl ${ }^{* *}$

À memória do prof. Arivaldo Montalvão Filho

Resumo

Com base no estudo do itinerário militante de líderes associativos no Estado de Sergipe, o artigo discute as condições de constituição de espaços de militância associativa, assim como as dinâmicas dos processos de engajamento e de militância individual. 0 trabalho dá atenção particular à militância múltipla e aos vínculos entre militância associativa e partidária.

Palavras-chave: Engajamento; Militância associativa; Politização; Participação política.

* Com algumas poucas alterações, este texto foi publicado originalmente em Oliveira, W. J. F. de. (org.) "Engajamento e militância política em Sergipe: contexto político, engajamento individual e atuação profissional". São Cristóvão: EDUFS, 2014, pp. 71-94.

** Doutor em Ciência Política. Professor do Departamento de Sociologia e Ciência Política da Universidade Federal de Santa Catarina. Bolsista de Produtividade do CNPq. Email: ernestoseidl@gmail.com 


\title{
Spaces of Politicization and Processes of Engagement in the Brazilian State of Sergipe
}

\begin{abstract}
Based on the study of the militant itineraries associative leaders in the Brazilian State of Sergipe, the article discusses the conditions of constitution of spaces of associative militancy, and the dynamics of processes of engagement and individual militancy. The work pays particular attention to the phenomenon of multiple militancy, and to the links between associative and militancy in political parties.
\end{abstract}

Keywords: Engagement; Associative militancy; Politicization; Political participation.

\section{Espacios de politización y procesos de compromiso en el Estado de Sergipe}

Resumen

A partir del estudio del itinerario militante de líderes asociativos en el Estado de Sergipe, Brasil, el artículo discute las condiciones de constitución de espacios de militancia asociativa, así como las dinámicas de los procesos de compromiso y de militancia individual. El trabajo da atención particular a la militancia múltiple y a los vínculos entre militancia asociativa y partidaria.

Palabras-clave: Compromiso; Militancia asociativa; Politización; Participación política 


\section{Introdução}

O conjunto de reflexões apresentado neste artigo é fruto de pesquisas que realizei no Estado de Sergipe entre 2007 e 2012 em torno de preocupações ligadas ao tema da militância ${ }^{1}$. De modo sintético, diria que os eixos da problemática giravam em torno de duas dimensões principais: as condições de constituição de espaços de militância associativa em Sergipe; e as dinâmicas dos processos de engajamento e de militância individual, com atenção à militância múltipla e aos vínculos entre militância associativa e partidária.

À época da realização das pesquisas e da apresentação de seus resultados, chamava a atenção para a inexistência de trabalhos dedicados aos movimentos sociais e à militância no Estado de Sergipe; fato que, a meu ver, estimulava a geração de pesquisas e, ao mesmo tempo, também dificultava um tanto os esforços iniciais dos pesquisadores pela falta de pontos de referência. De lá para cá, o panorama de investigações acadêmicas dedicadas ao engajamento e à militância avançou de modo considerável²

1 Parte dessas pesquisas contou com apoio da Fundação de Apoio à Pesquisa à Inovação Tecnológica do Estado de Sergipe (FAPITEC/SE) por meio de financiamento de projeto de pesquisa, e também da Universidade Federal de Sergipe, com o Programa Institucional de Bolsas de Iniciação Científica (PIBIC). Uma primeira apresentação desses resultados encontra-se em Seidl (2009a; 2009b; 2014a, 2014b) e Seidl; Leandro (2012) e é em parte aqui retomada.

2 Esse avanço é fruto, sobretudo, de pesquisas levadas a cabo de forma sistemática pelos membros do Laboratório de Estudos do Poder e da Política (LEPP/UFS), liderado por Fernanda R. Petrarca e Wilson J. F. de Oliveira. Além da coletânea organizada por Oliveira (2014), que compila uma primeira fornada de estudos originais, já são numerosos e diversificados os trabalhos voltados à militância em Sergipe. Afora os diversos trabalhos publicados por aqueles dois pesquisadores e por seus orientandos (ver mais em https:// leppufs.weebly.com/), destaco de modo sumário as pesquisas de Neves $(2000 ; 2012)$ e de Souza (2009; 2012), sobre o "movimento negro", de Carvalho (2013), sobre militância de leigos católicos, e de Figueiredo (2012), sobre a "condição de professor" e investimentos na esfera política. Para uma visão sobre os estudos em torno do engajamento e da militância no Brasil, ver Oliveira (2013) e Silva; Ruskowski (2016); e sobre a vertente francesa, que tem inspirado em especial os trabalhos mencionados, consultar Sawicki; Simméant (2011). 
embora sejam ainda grandes as lacunas em especial pelo lado da historiografia.

Seja como for, dadas as dificuldades de realizar um levantamento histórico circunstanciado das instituições, grupos e "movimentos" de caráter associativo no Estado, optei pela tentativa de reconstituição do espaço de mobilização política por meio do estudo de itinerários sociais de dirigentes e ex-dirigentes de entidades sediadas na cidade de Aracaju. Vale dizer, apesar da consulta a fontes institucionais, o principal expediente utilizado foi o registro oral de narrativas biográficas associadas à formação de grupos ou organizações ativistas. Mais especificamente, o material mobilizado como fonte de informação é constituído, em seu grosso, de entrevistas biográficas com líderes e ex-líderes de organizações de portes distintos e dedicadas a questões diversas: defesa de homossexuais, ambientalismo, filantropia, sindicatos de professores universitários e de petroleiros, religião católica, movimentos negro e afrorreligiosos e Movimento dos Trabalhadores Rurais Sem Terra.

É importante sublinhar que os casos aqui examinados não envolvem formas de militância ocasional, de adesões a título apenas formal ou de participações pontuais em instituições associativas, mas de investimentos pessoais intensos - mesmo que nem sempre lineares ou contínuos - em espaços nos quais os indivíduos viriam a ocupar posições de liderança ou destaque.

\section{Espaços múltiplos de inserção}

Uma das principais constatações feitas a partir do exame dos itinerários sociais dos indivíduos em questão aponta uma militância ativa de grande parte deles em partidos políticos. Em boa medida, esse envolvimento partidário ocorre de modo simultâneo ao engajamento associativo e, com frequência, o precede. Tal constatação sugere, em primeiro lugar, certa relativização das conclusões de pesquisas internacionais que apontam uma 
dissociação entre militância associativa e militância partidária, da qual emergiriam comprometimentos mais especializados e voltados a "causas" específicas nos "novos movimentos sociais" (Perrineau, 1994; Matonti; Poupeau, 2004). Esses elementos estariam inseridos, segundo as indicações, em tendências mais de fundo das formas de engajamento e militância. Por um lado, uma menor atração exercida pelos espaços e formas tradicionais de participação (partidos e sindicatos); por outro, a diversificação ou alargamento das modalidades de engajamento político, aliado a um processo de individuação e de personalização objetivada, sobretudo, em espaços associativos dos mais variados. Assim, inicialmente, me parecia plausível formular a hipótese de que a relativa escassez de espaços associativos mais profissionalizados e especializados - sobretudo ONGs - e, portanto, a estrutura limitada tanto de formas de cooptação e de recrutamento quanto de possibilidades de realização de carreiras militantes, tenderia a proporcionar uma configuração de militâncias que entrelaçam inserção associativa e partidária (Seidl, 2009a).

Por outro lado, estudos realizados no Brasil com participantes e promotores do 5ํ Fórum Social Mundial, sediado em Porto Alegre/RS em 2005 (Coradini, 2008), e com militantes do Partido dos Trabalhadores (Gaglietti, 2003) e dos movimentos ambientalista (Oliveira, 2005) e Economia Solidária no Rio Grande do Sul (Silva; Oliveira, 2011) - portanto, em configurações muito distintas da sergipana - também destacam a alta relação entre pertencimento associativo e política partidária ${ }^{3}$. Progressiva-

3 A pesquisa de Coradini com mais de dois mil entrevistados mostrou que $81,6 \%$ dos indivíduos que participavam de algum movimento ou organização social eram filiados a partidos. Desses, a maioria pertencia a sindicatos e associações de classe $(25,7 \%)$ e ONGs (20,0\%). Tomando a questão por outro ângulo, Gaglietti (2003) revelou que 94,5\% dos militantes do PT estudados em sua pesquisa passaram por movimentos coletivos como o estudantil, sindical, comunitário e religioso, embora parcela expressiva tenha se declarado, no momento da pesquisa (final dos anos 1990), não engajada nos "movimentos sociais e populares". Essas tendências são confirmadas pelo extenso trabalho de Paludo (2017) com militantes petistas em nível nacional. 
mente, pois, a formulação mais acima deixava lugar para novos questionamentos. Entre eles, a evidência de que a proliferação de entidades associativas ligadas às mais diversas "causas" e responsáveis por novas formas de pensar, falar e agir politicamente, no Brasil, parece em nada excluir a manutenção de vínculos com partidos políticos e sindicatos, duas instituições clássicas do espaço político ${ }^{4}$.

Por essa ótica, a estrutura de oportunidades políticas ao ativismo associativo teria uma relação mais complexa com a adesão ou não a agremiações partidárias, isto é, a alta imbricação entre aqueles espaços não seria necessariamente resultado de uma baixa oferta para atuação associativa a indivíduos que, num suposto contexto de desinteresse pelos partidos - "descrença", "desgaste”, "ineficácia”, "alta profissionalização dos quadros" -, buscariam participar ativamente da política por outros canais. Ao que tudo indica, a questão central estaria ligada a características estruturais do espaço político no Brasil, marcado por alta intersecção entre sindicatos, associações e partidos políticos e, em especial, forte dependência daquelas instâncias frente à órbita estatal 5 .

Assim, a autonomia relativamente baixa do polo não-partidário da política frente ao polo partidário e ao Estado ou, por outro ângulo, o predomínio dos partidos e da esfera estatal em termos de capacidade de mobilizar recursos, definir e legitimar os temas da agenda social e política e, enfim, produzir resultados, gerar dividendos, ajudaria a explicar a importância de indivídu-

\footnotetext{
4 Um levantamento exploratório de instituições associativas apenas na capital Aracaju, cidade com então cerca de 500 mil habitantes, apontou 34 entidades identificadas com a "causa de crianças e adolescentes", 29 com a "defesa portadores de necessidades especiais", 17 com o "movimento negro", 10 com o "combate à homofobia", 3 com a "causa das mulheres" e 3 com a "causa ambiental".

5 Sobre as ambivalências entre militância partidária e associativa em grupos voltados à causa da "mobilidade" e do "transporte" urbanos, consultar Santos (2014) e Seidl; Garcia (2017).
} 
os devotados à intervenção política, quaisquer que sejam suas "causas", estarem inseridos em partidos. Este dado explicaria, por sua vez, a dificuldade de afirmação de uma esfera associativa mais densa e com maior poder; isto é, não apenas com maior capacidade de atrair indivíduos para participar, mas também em melhores condições de retribuí-los ou satisfazê-los material, simbólica e psicologicamente.

Nossa historiografia política tem dado indicações claras sobre o padrão de relações entre Estado, partidos e movimentos sociais no Brasil republicano, destacando a proeminência da esfera estatal e as estratégias de cooptação frente a sindicatos, partidos e movimentos, e também os ciclos de mobilização/repressão ligados às variações do regime político. Como demonstrado pela literatura, o período recente conhecido como abertura e redemocratização teve como atores centrais, pelo lado dos contestadores, certo tipo de sindicalismo vinculado intimamente ao Partido dos Trabalhadores, a Igreja católica como instituição (mas também certos grupos e tendências em seu interior) e algumas associações profissionais, sobretudo a Ordem dos Advogados do Brasil (Gohn, 1995; 2010; Landim, 2002; Mische, 1997; Sader, 1988).

Ressalte-se também que, durante a vigência do regime militar, o principal modelo de atuação militante dos chamados movimentos clandestinos, incluindo as guerrilhas, era o partidário ${ }^{6}$. Em síntese, o mais importante a reter nesse sentido é o papel e o peso decisivos de partidos, de sindicatos e da Igreja católica na constituição de organizações e de movimentos sociais - rotulados pelas Ciências Sociais brasileiras como "novos movimentos sociais" - que floresceram a partir do final da década de 1970 e

6 No entanto, é preciso lembrar, como o faz Barthélémy (1994, pp. 89-90), que do ponto de vista das estruturas e dos comportamentos individuais, são grandes as semelhanças entre a atividade associativa e outras formas de participação na vida pública. Inclusive, muitas associações se constituíram no seio de partidos e de sindicatos, integradas a esferas de influência ideológica e a constelações de ideias. 
cujo espaço de atuação, ao longo dos anos 1980 e 1990, conheceu fortíssima expansão e diversificação. De um lado, a Constituição de 1988 garantia legitimidade jurídica ao associativismo e, de outro, o repertório de causas expandia-se e as formas de organização modificavam-se, com destaque ao vigor do modelo das organizações não-governamentais.

Como mostrou Landim (1998), a primeira geração das denominadas ONGs brasileiras foi formada, em sua essência, por quadros estreitamente ligados a igrejas e a correntes marxistas - agentes sociais com forte experiência de militância política (anistiados, por exemplo), melhor dotados em cultura e em relações pessoais e, frequentemente, com inserção no universo acadêmico. Nessa posição, foram centrais no processo de institucionalização dos grupos, na elaboração de discursos legitimadores de suas causas e intenções e, por esta via, na própria conformação de um espaço profissionalizado de ativismo ${ }^{7}$. Para muitos, portanto, a atuação nessas instâncias oferecia oportunidades de rentabilizar uma competência política acumulada ao longo de seus itinerários sem necessariamente ingressar nas disputas partidárias - para alguns, inclusive, bloqueada, isto é, podiam continuar a fazer política por outras vias, atualizando assim a lógica individual de seus engajamentos ${ }^{8}$.

Mas o caminho inverso na militância também é frequente, e talvez seja viável esboçar a hipótese de uma tendência ao envolvimento em modalidades associativas preceder a militância partidária. Embora não se disponham de dados mais exaustivos que forneçam detalhes sobre itinerários militantes, sabe-se,

7 Revelador do êxito de parte dos empreendimentos dessa geração, é enorme o peso de ONGs ligadas a certos de seus integrantes na formação da Associação Brasileira de Organização Não Governamentais (ABONG), peça-chave na organização do Fórum Social Mundial no Brasil, como demonstrado por Coradini (2008).

8 Exemplos de trajetórias de militantes políticos "que lutaram contra a ditadura" e tiveram destinos políticos e profissionais marcados por esta experiência são analisados por Reis $(2007 ; 2008)$. 
em todo caso, que a militância associativo-sindical tem exercido papel crescente nos mecanismos de legitimação do espaço partidário no Brasil. No contexto atual, as condições de entrada e de sucesso em disputas eleitorais têm dependido cada vez mais de vínculos previamente estabelecidos com associações e sindicatos. Inclusive, detecta-se que as concepções sobre pretensões ao exercício de funções eletivas implicam crescentemente a exibição de algum tipo de liderança associativa prévia, como demonstram algumas pesquisas (Coradini, 2001; 2007; Seidl; Leandro, 2012).

Em suma, tem-se no capital associativo um componente de peso no processo de especialização política. Esta tendência também é encontrada nos casos que examinei em Sergipe, os quais apontam a importância de atuações em espaços participativos, notadamente em movimentos estudantis e sindicatos, como portas de entrada para os partidos ${ }^{9}$. Seguramente, as transformações das últimas décadas na configuração do espaço político estadual acompanharam tendências gerais de diversificação das bases sociais do pessoal político e de novas formas de composição de recursos que conformam modalidades mais variadas de carreira política. 0 êxito de grupos e de agentes cujos itinerários estão ligados a concepções militantes do jogo político em Sergipe sem dúvida dá provas desse processo ${ }^{10}$.

Como veremos, combinados com outros elementos, aqueles espaços foram determinantes nos processos de politização de

9 É preciso estar atento, por outro lado, à centralidade que têm as experiências acumuladas em partidos e em sindicatos na afirmação de lideranças (ainda que negadas com veemência como tal!) de grupos cujas referências e estratégias de legitimação no espaço político justamente se opõem, de modo radical, àquelas formas de fazer política, como é o caso de diversos "coletivos" e "movimentos". Refiro-me aqui em especial ao Movimento Não Pago e ao Movimento Passe Livre. Cf. Santos (2014) e Seidl; Garcia (2017).

10 Sobre a ascensão de novos grupos políticos no Estado de Sergipe, ver Dantas (2002). Para um perfil social e de carreira dos deputados estaduais, consultar Steckel (2007), e sobre a composição dos secretariados estaduais, Seidl; Leandro (2012). 
indivíduos que investiriam no jogo político em intensidade e formas variadas. Neste sentido, a análise levada a cabo procurou matizar com cuidado os elementos que explicam o fenômeno da militância múltipla. Sem desconsiderar as variáveis mais estruturais, a abordagem dos processos de engajamento e das lógicas de investimento na militância combinou aquela dimensão com a das interações sociais, a qual conduziu à análise das redes sociais e da construção de sentido vivenciada pelos indivíduos ao longo de suas biografias (Passy, 2005).

\section{Processos de engajamento}

Se ninguém nasce militante, como recorda Fillieule (2001), mas alguns indivíduos tornam-se militantes - de forma "durável" ou "provisória" -, segundo o contexto e as circunstâncias próprias às trajetórias pessoais, tomar este fenômeno como "processo" é questão central. Como apontado por outros estudos sobre militância associativa no Estado de Sergipe (Matos, 2010; Melo, 2012; Nascimento, 2011; Seidl, 2009a, 2009b; 2014a, 2014b; Sousa, 2010; Souza, 2009; 2012), as condições sociais de engajamento individual encontradas naqueles contextos remetem a experiências de socialização primária e secundária favoráveis à constituição de disposições à participação em atividades coletivas. No espaço familiar amplo, destaca-se forte integração social de seus membros em atividades partidárias, associativas e religiosas via sindicatos, partidos, associações de bairros e religiões. Mesmo que nem sempre explicitada ou compreendida como "política", essa série de experiências práticas que atravessam o universo familiar dos futuros militantes tem impacto sobre a formação de percepções das relações sociais e de modelos de sociabilidade e de atuação que são marcados pelo envolvimento em espaços coletivos. A valorização de uma ética social orientada por princípios religiosos, sobretudo de matriz cristã, também compõe os ambientes em que grande parte dos militantes cresceu e chegou à adolescência. 
De modo significativo, parcela expressiva deles envolve-se já naquele período da juventude em grupos e atividades orientadas por noções como "participação", "caridade”, "ajuda”, "cooperação”, os quais se baseiam em modelos "deliberativos", “democráticos", "participativos" - como os grupos de jovens e as pastorais ligadas à Igreja católica, os escoteiros e os grêmios estudantis. Assim, embora não se trate de forma alguma, ressalte-se bem, de estabelecer aqui uma determinação direta ou mecânica entre condições socioculturais e engajamento, tais condições são tomadas como fator central para a compreensão dos processos de engajamento exibidos nos itinerários de militância que examinamos.

É preciso recordar, por outro lado, que todo processo de engajamento resulta do encontro entre disposições e expectativas individuais (prévias ou não) e estruturas de oportunidades de ação (Gaxie, 2005). Vale dizer, qualquer envolvimento em algum grupo, causa ou mobilização coletiva somente pode se realizar em contextos que permitam que indivíduos atribuam sentido a algum tipo de ação participativa. Isto diz respeito não apenas, por exemplo, a alguém que, em dado momento da vida, resolve aderir a um grupo, digamos, uma ONG ambientalista. Ou seja, que encontra uma oportunidade para agir concretamente e satisfazer uma vontade pessoal de intervir no mundo com finalidades específicas. Refere-se também aos casos de indivíduos que decidem criar um grupo ativista ou dar início, digamos, a uma associação de bairro, processo que igualmente exige uma constituição prévia de valores e preferências que o levam à ação.

Por sua vez, para que tal ação se desenvolva, ela também depende do contexto histórico, político e cultural de um determinado local e de um determinado momento, pois sabe-se que as configurações políticas e períodos não suscitam o mesmo nível de engajamento militante (Juhem, 2001). Como exemplo, pode-se citar o período de regime militar brasileiro como determinante, em primeiro lugar, na criação de quadros de referência/sentido 
(alguns diriam framings) para a ação e, em segundo lugar, na formação de grupos e movimentos mobilizados, entre outras "causas", pela "redemocratização" e "reconstitucionalização", pela "defesa dos direitos humanos", pelo "fim da tortura". Ou então, opostamente, o período de restabelecimento da democracia, que deu novo impulso à parte das "causas" já existentes - com garantias constitucionais - e favoreceu a constituição de novas causas até então com pouco ou nenhum espaço na agenda política nacional, como o "ambientalismo", as "questões raciais", a "homofobia", o "combate à AIDS"11. Pode-se ainda mencionar a relação entre a ausência de políticas governamentais efetivas e constantes de distribuição agrária e o surgimento de mobilizações que constroem esta "causa" e se afirmam em torno dela, como é o caso do Movimento dos Trabalhadores Rurais Sem Terra.

Como procurei indicar mais acima, os indivíduos tomados como referência para este estudo são ou foram lideranças (ou figuras de destaque) de seus respectivos grupos. Não estranha, portanto, que a quase totalidade dos casos revele engajamentos com intensidade relativamente alta, grau importante de estabilidade e pouca flutuação, uma vez que tais posições são resultado de investimentos intensos ao longo do tempo, inclusive com diversos casos de profissionalização via militância.

Se suas condições de socialização familiar e as experiências de participação coletiva na adolescência aparecem como fatores favoráveis à adesão a alguma forma de mobilização, a inserção em novas redes sociais, sobretudo a partir do ingresso no ensino superior, - mas, também, na esfera do trabalho -, representa momento central para a definição de seus engajamentos e militâncias futuros. Aqueles cujo envolvimento prévio em grêmios escolares, escoteiros ou grupos religiosos fornecera alguma inti-

11 Para uma análise do efeito das transformações em âmbito internacional da "questão do racismo" sobre a esfera estatal brasileira e seus impactos no "movimento negro", consultar Souza (2012). 
midade com espaços coletivos tendem a encontrar na universidade terreno para ampliar sua atuação. Em primeiro lugar, e de forma mais visível, tem-se os casos de ex-membros de grêmios que ingressam no movimento estudantil e integram o comando de diretórios acadêmicos, como ilustra o caso de um ex-líder de grêmio de uma escola técnica federal, ligado ao PCdoB antes de iniciar o curso na universidade, ex-presidente do Diretório Acadêmico Estudantil (DCE) por duas gestões, então coordenador da recém-criada Coordenação Municipal de Juventude, controlada pelo PCdoB, e secretário de Juventude do partido.

Conforme demonstrei em outro lugar (Seidl, 2009a, 2014b), embora mais evidente e efetiva, não apenas a participação em movimentos estudantis aparece como canal de exposição à lógica do engajamento e do ativismo na arena escolar. As possibilidades de envolvimento abertas a jovens universitários em projetos "sociais" por meio de ações concretas e intensas como "educação popular", "mutirões de solidariedade”, cursos de saúde básica, por exemplo, também figuram como arena de socialização política importante. Em alguns casos, tais experiências são apontadas pelos entrevistados como um "início no social" e funcionariam como uma espécie de prova de "sensibilidade" e de "comprometimento". Como em todos os casos examinados, o olhar retrospectivo lançado pelos militantes sobre suas biografias não deixa de tentar encontrar elementos que busquem confirmar a "coerência" de suas opções e investimentos.

\section{Espaço escolar e ativismo político}

A importância do espaço acadêmico nas condições de engajamento e de militância deve ser considerada especialmente pela centralidade que tem na criação de novos vínculos e na subsequente inserção dos indivíduos em redes de sociabilidade que podem ser decisivas tanto na redefinição de engajamentos preexistentes quanto na realização de novos, ou, ainda, ambas as 
coisas. Essa afirmação pode ser ilustrada, por um lado, com os casos de indivíduos que entram na universidade sem nenhum tipo de militância anterior (ou somente contando participação em algum grupo não ativista) e, pelo efeito de contatos com colegas, amigos e professores, envolvem-se gradativamente em grupos do movimento estudantil, da militância negra, homossexual, MST e partidos políticos.

Por outro lado, também pode ser exemplificada com casos de indivíduos já vinculados a partidos e/ou outras formas de participação militante ao entrarem no ensino superior. Para esses, com frequência a universidade abre oportunidade para uma intensificação do ativismo - via política estudantil e, muitas vezes, em tarefas de recrutamento de militantes para o partido -, mas, também, para uma diversificação do engajamento; por exemplo, com a inserção em outros grupos e a adesão a outras "causas". Seja como for, a amplificação e adensamento das redes de relações sociais favorecidos pela circulação no espaço escolar é um dos mecanismos mais fortes nos processos de recrutamento tanto para a militância associativa quanto para a partidária, propiciando militâncias múltiplas.

Mas além da sociabilidade e da formação de bases de interconhecimento privilegiadas pela esfera escolar, a relação entre escolarização superior e militância precisa ser tomada pelo ângulo do próprio engajamento. Isto porque a escolha inicial de determinados cursos e/ou disciplinas pode estar orientada por uma concepção política da formação e/ou da profissão buscada, casos em que a profissionalização é tomada como uma forma de militância, como demonstra, por exemplo, o trabalho de Cândida Matos (2010) sobre as assistentes sociais em Sergipe. Essa constatação, aliás, é mais ampla em configurações como a brasileira, em que “o sentido e o valor da 'profissão' são inseparáveis do 'compromisso com uma 'realidade' que é 'totalmente política'”. Ou seja, "a formação escolar e o exercício profissional requerem a capacidade ou competência de "comprometimento" da forma- 
ção escolar e técnica com "a realidade" e com a 'prática'” (Oliveira, 2012, p. 23).

Isso é especialmente visível nos casos de militantes cuja principal ocupação é o magistério em nível médio ou superior, para os quais a atuação como professores é indissociável da militância e as retribuições (simbólicas e materiais) dependem das possibilidades de intervenções concretas "na realidade" por meio da "conscientização", "politização", "mobilização” de seus públi$\cos ^{12}$. Essas intervenções raramente se restringem ao espaço de sala de aula e incluem, no âmbito institucional, envolvimento sindical e disputas por cargos administrativos e, fora dele, ativismo em diferentes espaços: partidos, movimento de leigos católicos, grupos de jovens, ambientalismo, Movimento dos Trabalhadores Sem Terra, "educação popular".

O papel de mediadores que esses indivíduos executam entre esfera acadêmica e institucional e outras esferas de inserção militante pode adquirir contornos variados em função da intensidade do ativismo e também das contingências instáveis das relações com os grupos. De um modo geral, inclui em alguma medida o exercício da figura de "intelectual orgânico", ou de "autoridade científica", com legitimidade para falar ao grupo e sobre a "causa" e, em alguns casos, falar pelo grupo; mas este papel também comporta tarefas de difusão da "causa" e do grupo e de recrutamento de adeptos entre alunos e colegas, facilitando contatos por meio da indicação de leituras e de certos esquemas de compreensão e, não raro, convidando para eventos como reuniões, palestras, acampamentos, visitas a assentamentos, entre outros.

12 Sobre as ambiguidades e os usos moralmente valorativos do termo "politização", ora como algo positivo, ora, negativo, ver o excelente artigo de Lagroye (2017). 
Então, quando eu entrei na escola [técnica federal], o MST tinha feito uma ocupação das terras da escola; aí tinha uns professores... o professor $X$. foi o cara que começou a desenvolver um trabalho de apoio ao movimento social, aí eu comecei a me aproximar, a partir dessa ocupação. A gente ia no final de semana dormir no assentamento, ter contato com as pessoas do MST. Um tempo depois eu fiz um curso de formação militante de seis meses com o MST. Todo final de semana eu ia pra lá e reuniam jovens do estado inteiro, uns 200 jovens, lideranças jovens do MST. Era um curso sobre tudo, um curso sobre a origem do MST, sobre a questão fundiária do Brasil, como se deu a regulamentação, por que a luta pela democratização da terra. Tinha teses de como fazer uma ocupação, era uma espécie de treinamento para ocupação, de resistência, de montar barraca e tinha questões mais políticas (...).

Eu ganhei o "Manifesto Comunista" de presente de um professor da escola técnica, professor de Filosofia. (...) foi mais porque o movimento sindical [de professores] tinha tirado uma resolução de apoio à ocupação, então ele falava em sala de aula. Tinha um camarada do meu quarto que se chamava Y. Aí a gente despertou o interesse. Quem fundou o grêmio lá foi eu e ele. O grêmio estava fechado desde 93 e a gente refundou.

Sinceramente, quem é militante político acha que a UFS é o grande reduto, é o grande reduto da militância, daquilo que se pensa e tal. (Ex-presidente de DCE, coordenador de Juventude do PCdoB).

Seria ainda necessário destacar outra dimensão fundamental das relações entre espaço escolar e militância (ou politização), a qual diz respeito à intensificação e diversificação de investimentos na aquisição de recursos culturais - diplomas superiores, especializações, pós-graduação stricto sensu - e sua utilização como trunfos na militância partidária e associativa (Coradini, 2001; 2002; Gaglietti, 2003; Grill, 2007; Oliveira, 2007; 2009b; 2009c). Sem dúvida, esse fenômeno liga-se em primeiro lugar ao processo mais amplo de fortíssima expansão da escolarização superior no Brasil, com acentuada desvalorização relativa de 
boa parte dos diplomas, e um efeito em cascata de proliferação de cursos de pós-graduação de todos os tipos. Mas se o grau de escolarização da população brasileira aumentou de modo geral, o que interessa perceber são os efeitos deste incremento no uso dos títulos escolares como recurso para afirmação no espaço da política, tanto em seu polo associativo quanto no partidário-eleitoral.

Assim, como dito mais acima, se as concepções dominantes sobre profissão no Brasil enfatizam a politização dos espaços de atuação, tem-se que o próprio interesse em determinada formação, ou seu critério de avaliação, envolva as "possibilidades de sua utilização instrumental para a conquista de cargos ou então outra função 'prática' qualquer" (Coradini, 2002, p. 106). E, mais do que apenas uma titulação formal maior e mais diversificada, com crescente valorização das Ciências Sociais, estão em jogo as diferentes formas de mobilização dos títulos segundo as esferas de militância envolvidas. Em outras palavras, as condições de legitimação no espaço político exigem crescentemente a exibição de diplomas acadêmicos, embora estes somente tenham eficácia em combinação com outros recursos, como tempo de militância, redes de relações e inserções em outras esferas sociais, recursos econômicos.

Filho de um ex-seminarista menor, médio proprietário de terras no interior de Sergipe, e de uma dona de casa que completou o ginásio, contando tios-avós políticos em ambos os ramos familiares, J. nasceu no início dos anos 50 e realizou todo seu itinerário escolar numa escola católica de elite na capital do Estado. Criado em ambiente fortemente religioso, lembra que desde a juventude gostava de participar de movimentos e grupos e "se interessava por política". A aproximação com o espaço estudantil secundarista configura um primeiro contato com o universo das disputas políticas. Aos quinze anos é eleito presidente do Grêmio estudantil, durante os "anos de chumbo". Ao concluir a escola, ingressa no curso de Química Industrial na Universidade Federal, ins- 
tituição que o admitirá como professor dois anos após sua formatura. Católico praticante desde a infância, J. intensifica o envolvimento com a Igreja através de cursilhos que coordena dentro do quadro da diocese de Aracaju. Esta ligação com o catolicismo perdurará por muitos anos e também estará vinculada com sua participação no Partido dos Trabalhadores - do qual diz ser "fundador", embora à época ainda não fosse filiado. A inserção de J. na universidade é acompanhada da intensificação de atividades militantes e da ampliação de redes sociais que o conectam com o envolvimento partidário. 0 engajamento na fundação da Associação dos Professores da UFS (que presidirá dez anos mais tarde) coincide com aquela no PT, partido ao qual se filiará também uma década depois. Por sua vez, parte do conjunto de relações tecidas nesses dois espaços, em especial no partidário, desdobra-se no conselho de leigos católicos em que atua. J. dá ênfase à "politização" daquele espaço: "éramos a vanguarda, discutíamos muito política social, educacional". Desses vínculos intensos diz ter saído a indicação de seu nome à candidatura a deputado estadual, na qual não teve sucesso. Dizendo-se "frustrado" com a campanha política e com os resultados do governo do PT no país, J. desfilia-se do partido, porém logo em seguida ajuda a fundar o PSOL em Sergipe, compromisso que será efêmero por conta de suas discordâncias com o "radicalismo". Embora longe dos partidos, segundo ele, o afastamento da militância partidária não comprometeu seus princípios. "Acho que nossa militância na educação é forte, porque a gente pode influir bastante na realidade. Descobri que a universidade é a vida da gente, mas é claro que a gente tem que influir fora também; isso eu consegui com a Igreja e os movimentos sociais".

Exemplo típico de uma modalidade de combinação de recursos militantes são os casos de indivíduos que associam a um capital militante acumulado ao longo do tempo de ativismo - através de experiências e de contatos - a aquisição de títulos acadêmicos que tendem a lhes conferir, com legitimidade, maior competência e prestígio frente ao grupo. Com frequência, mesmo quando não se encontram em posições de liderança, esses militantes são solicitados a falar em nome do grupo em atividades que cobram alguma forma de competência intelectual. Por outro lado, 
como me relataram muitos militantes de grupos e movimentos diversos, são flagrantes as tensões geradas pelas disputas na legitimação entre diferentes recursos e concepções de militância (ou de "fazer política", como dizem), como a maior ou menor importância "dos estudos" frente à "experiência" e à "história" no movimento. Nas palavras de um militante partidário e do movimento negro: "Depois que entrei no mestrado (em Sociologia), o pessoal começou a me olhar assim de outro jeito. Alguns, desconfiados. Mas têm muito respeito por mim".

Significativamente, a grande procura de militantes por cursos de pós-graduação na área de Ciências Sociais na Universidade Federal de Sergipe - com altíssima correlação entre "temática de estudos" e interesse militante - dá indicações sobre as possibilidades de rentabilização dos títulos escolares na dinâmica da militância em Sergipe. Obviamente, esses investimentos também estão ligados a alternativas de profissionalização no magistério. Embora não se trate, em sua maioria, de militâncias de expertise, como se vê no movimento ambientalista brasileiro (Oliveira, 2009b; 2009c), a aquisição de diplomas chancelados por universidades tem efeitos importantes na estrutura do capital militante detido. São assim incrementadas a autoridade social e as chances de ocupação de cargos de direção do movimento ou partido e/ou realização de atividades mais especializadas, como em comissões ou secretarias temáticas de partidos e na administração pública, em instâncias específicas como secretarias, subsecretarias e órgãos de níveis variados.

Não se pode perder de vista, por outro lado, o efeito do processo de institucionalização e profissionalização da militância sobre a relação escolarização-militância. Como sabido, são crescentes as exigências por qualificações que dependem de diplomas escolares à medida que o acesso aos espaços e processos formais de produção de políticas do Estado, - mas, também, aos canais de financiamento de projetos públicos e privados, - passam a depender não somente da institucionalização dos grupos, mas, 
igualmente, da exibição de quadros profissionalizados e de especialistas ou experts. Novamente, entram em conta a aquisição e mobilização de recursos escolares diretamente orientados pela lógica da militância, com chances palpáveis de retribuição.

Boas indicações desses processos foram observadas no caso de um grupo de indivíduos com características que chamaríamos de empreendedorismo militante. Trata-se de militantes que, entre os 20 e 30 anos de idade, investiram na criação de ONGs "ambientalistas" e de "defesa de homossexuais", das quais se tornaram eles próprios dirigentes. Devido à instabilidade de financiamento para realização de projetos e remuneração regular de pessoal, as condições de profissionalização militante desses indivíduos são limitadas. Assim, combinam uma vida profissional de professores de nível fundamental e superior - todos com titulações que variam de especialização a doutorado, com o caso extremo de um militante ambientalista exibindo em seu currículo Lattes cinco especializações, além de mestrado (Desenvolvimento Ambiental) e doutorado (Ciências Sociais) - com intensa dedicação a associações relativamente estruturadas. É por meio delas que obtêm recursos, de forma irregular, através de projetos financiados por órgãos do Estado ou do setor privado. Embora não se disponha de dados precisos sobre o grau de profissionalização da militância associativa em Sergipe, há fortes indicações de que predominem situações como essas, em que o ativismo combina-se com o exercício de uma profissão estável e remunerada.

É preciso, por fim, fazer referência aos casos de militantes cujas condições de acesso a recursos escolares e de sua utilização, mais do que representarem resultado direto do vínculo com algum movimento, encarnam estratégias de investimento do grupo na formação de quadros e lideranças. Não por acaso, os dois itinerários que apresentam essa dimensão são de militantes do Movimento dos Trabalhadores Sem Terra, uma organização bem estruturada e articulada com diversos outros grupos, institui- 
ções e esferas sociais, tais como a Igreja católica, as burocracias do Estado, sindicatos, escolas e universidades. Ambos os casos referem-se a indivíduos com envolvimento prévio em sindicatos e associações rurais e com o Partido dos Trabalhadores e, em um dos casos, com um grupo católico, em pequenos municípios do interior.

Agora, antes de me organizar no MST, eu já era da Pastoral da Juventude e do Partido dos Trabalhadores, então, o meu vínculo com o PT é até anterior ao movimento; até hoje eu continuo. Tenho alguma ressalva... eu entrei no Partido dos Trabalhadores numa fase muito bonita, em que era muito próxima a luta do movimento com os ideais e com a luta do Partido dos Trabalhadores, era muito próximo..., como organizar as comunidades, a Igreja, o movimento da Igreja. Partido dos trabalhadores e Movimento Sem Terra, naquele momento, faziam praticamente a mesma coisa: organizar o povo, organizar os trabalhadores, organizar a comunidade; era esse o meu papel. Eu consegui muito rápido... transitava muito fácil entre Movimento Sem Terra, Igreja e Partido dos Trabalhadores.

Você entrou no MST... e sua entrada foi pela secretaria?

Foi pela secretaria. Na verdade, um processo inverso ao que a maioria dos jovens faz. É muito comum, o jovem entra, a família entra, depois o jovem acaba se envolvendo no MST. É, tem uma outra forma, não é tão comum, mas acontece também. São os jovens universitários que nos cursos, nos estágios de vivências, a depender do contato com algum professor, que tenha relação com o campo, acaba se aproximando do MST e entra. Nós temos alguns casos, mas o meu caso foi atípico. Eu fui convidado, eu fui um jovem convidado pro MST; depois é que minha família entra, e também não fui um jovem universitário; eu entro na universidade depois que eu estou no MST (militante e dirigente do MST e do PT.) 
As experiências políticas anteriores ao ingresso desses militantes no MST são expressivas e foram acumuladas em espaços com princípios de ação e de organização semelhantes aos do movimento em termos de esquemas de percepção social e de lógicas de lutas, de "constelação de ideias" (Ion et al., 1992), de vocabulário e ritualística. A adesão ao MST, inclusive, dá-se pela mediação daqueles outros espaços de politização. Como relatado, em um dos casos as experiências e contatos acumulados no sindicato, na Igreja e no PT permitem ao futuro "militante sem-terra" uma entrada "atípica", "por cima", no movimento, colocando-lhe rapidamente em funções de direção e de trânsito entre os diferentes espaços de ativismo. Graduando em Ciências Sociais à época de seu ingresso no movimento, "através" deste realiza uma especialização em "estudos latino-americanos" e, posteriormente, um Mestrado em Sociologia Rural, em universidades federais em dois estados diferentes. Há alguns anos é dirigente destacado do MST em Sergipe, integra a coordenação nacional do movimento, dirige um programa de rádio "sobre o MST" na emissora AM do governo do Estado e se apresenta, em seu Twitter, como dirigente do Partido dos Trabalhadores.

Veja só. Quando o Movimento Sem Terra investe, e tem investido, na formação de seus militantes, seja na área política, seja na área técnica [...] aí eu comecei a participar dos cursos do movimento, e ao mesmo tempo que eu estava acampado, comecei a participar de vários cursos do movimento... [...] como o movimento possibilita para todo mundo que queira estudar, o movimento foi me dando oportunidades e eu fui me envolvendo na militância, né? Fui me envolvendo; então, passei dois anos mais em acampamento e a partir desses dois anos em diante comecei a atuar na militância do movimento. [...] aí sim, já vim mais para Aracaju, né? Já vim pra Aracaju, pra outras atividades do estado (militante do MST, integrante da coordenação nacional). 
Essa especialização foi em Juiz de Fora; eu fiz uma especialização já através do movimento (MST). [...] o movimento proporciona muito isso, o acesso dos jovens, acampados, assentados, os filhos de acampados e assentados e militantes, acesso à educação, informal e formal. Tem muito curso de formação informal e muitos cursos formais em escolas de ensino médio e também universidade. 0 movimento fez uma parceria, talvez uma das primeiras parcerias, de curso formal com a escola, com a Universidade Federal de Juiz de Fora, e eu participei dessa primeira turma; foi a turma de curso de Especialização em Estudos Latinoamericanos.

0 mestrado eu diria que teve muita influência do movimento porque, quando eu entrei no mestrado, na verdade o curso era Sociologia Rural. [...] e nós tínhamos uma discussão na Via Campesina, que é essa espécie de guarda-chuva internacional da luta do campo, vários movimentos do campo no mundo inteiro [...] através da Via Campesina houve uma decisão de incentivar os jovens que já tinham curso de graduação dos movimentos, inclusive o MST, a participar de cursos de pós-graduação. (militante do MST, cerca de 40 anos, integrante da coordenação nacional).

No caso do outro militante - ex-membro da diretoria de um sindicato rural e ex-presidente de associação de moradores de seu povoado -, a adesão ao MST é mais gradual e ocorre após uma experiência de dois anos de "acampamento" e de cursos de "formação" no interior do próprio movimento ${ }^{13}$. Num primeiro momento, frequenta uma série de cursos ofertados dentro do sistema do próprio MST, que variam de questões ditas políticas, sobre "conjuntura", "justiça social e agrária”, a outras mais "técnicas", como organização de acampamentos, formas de cultivo, agroecologia e cooperativismo. É também por meio de convênio firmado entre o MST, a Universidade Federal de Sergipe, a

13 Sobre a relação entre recursos sociais e culturais, adesão e a elaboração de expectativas de retribuição à militância no Movimento dos Trabalhadores Sem Terra, consultar o trabalho de Coradini (2010). 
Fundação de Apoio à Pesquisa e Extensão de Sergipe (FAPESE) e o INCRA que obtém o título de engenheiro agrônomo em 2008. São nessas condições que adquire uma formação "técnica" na área ambiental, tornando-se coordenador da assistência técnica social e ambiental e integrante da direção nacional do movimento.

\section{Considerações Finais}

A questão central deste texto tratou de discutir as condições de realização de engajamentos militantes de tipo associativo no Estado de Sergipe. Para tanto, foi tomado como base um conjunto de casos de ativistas com elevado grau de envolvimento em grupos ligados a "causas" muito variadas. Para os propósitos específicos do trabalho, as dimensões privilegiadas pela análise foram os espaços de politização - tanto no sentido de aquisição de "competências políticas" (Gaxie, 1978) quanto no de atribuição de um "sentido político" a diferentes temas e esferas sociais (Lagroye, 2017) - identificados em diferentes etapas de seus itinerários individuais, com atenção especial ao espaço escolar, e a relação entre estas inserções e a composição de carreiras militantes.

O interesse pelos processos de engajamento no polo associativo da esfera política deriva não somente da relativa menor atenção dada pela literatura nacional a esta forma de engajamento ${ }^{14}$, mas, sobretudo, da relevância que o ativismo associativo tem nas modalidades de participação política no Brasil contemporâneo. Como demonstrado aqui e em outros estudos, a militância política no caso brasileiro raramente se resume unicamente a um tipo de envolvimento (associativo-sindical ou partidário). Pelo contrário, como sintetiza Oliveira (2012, p. 22), “uma das 
características das dinâmicas de configuração do engajamento e da militância política é que os militantes estejam inseridos simultaneamente em diversos tipos de organizações políticas e movimentos sociais".

Essa militância múltipla, que combina vinculações simultâneas a grupos e associações os mais variados - MST, catolicismo e religiões afro, direitos humanos, sindicatos, movimento negro, ambientalismo - com pertencimento a partidos políticos, indica ao mesmo tempo uma grande heterogeneidade e uma alta porosidade do espaço político. E se as arenas de participação, as formas de militância e as "causas" politizadas se multiplicaram de modo notável nas últimas três décadas ${ }^{15}$, isto é, o espaço político brasileiro tornou-se mais complexo e competitivo, é visível a importância dos partidos políticos como esfera de socialização, de alocação de recursos, de realização individual e também de profissionalização na militância.

Indiscutivelmente, a reconfiguração das oportunidades de participação política ocasionada pela reabertura de meados dos anos 1980 teve efeitos diretos nas condições de realização de engajamentos militantes, com a ampliação tanto das instituições partidárias quanto dos movimentos sociais e de seus atores. Assim, a articulação entre partidos e movimentos, através da incorporação de "causas" ou "bandeiras" dos movimentos pelos partidos, favoreceu o desenvolvimento de importantes canais e bases de recrutamento de militantes, inclusive com a criação de órgãos e postos partidários especializados em temáticas atreladas aos movimentos.

Da mesma forma, essas novas condições de disputa e de acesso ao poder burocrático-estatal passaram a acenar aos militantes 
com oportunidades de ocupação de cargos eletivos e de administração com base em recursos acumulados nos grupos e movimentos com os quais têm vinculação. Como visto, nesse contexto, a associação de recursos escolares mais diversificados com a militância aparece como componente central tanto para o ingresso quanto para a permanência na militância, dadas as possibilidades mais palpáveis de retribuição em termos de realização de ideais, de ocupação de cargos e de profissionalização.

A partir dos anos 2000, a ascensão ao poder de grupos partidários identificados com movimentos sociais "ligados a causas populares" e com diversas formas de militância associativo-sindical na esfera municipal (prefeitura de Aracaju, 2001), estadual (Governo do Estado de Sergipe, 2007) e federal (presidência da República, 2003) marca uma reconfiguração na dinâmica do espaço político. Nessa, certamente mais complexa do ponto de vista das concepções de política e de sociedade e de suas formas de legitimação, ganham força modalidades de fazer política pautadas por uma "visão militante" da política. Nestas condições, destaque-se, a militância em partidos e em outras esferas é tomada como principal critério para qualquer pretensão de ocupação de cargos ou para o exercício de liderança.

Num efeito de retroalimentação, as próprias concepções de "política" e de "sociedade" dominantes nesses grupos que assumem o poder favorecem a criação de mecanismos "deliberativos" (como o Orçamento Participativo, por exemplo) e de instâncias especializadas na elaboração e implementação de políticas voltadas a "causas" defendidas pelos movimentos sociais com os quais têm vínculos (secretarias de combate à discriminação racial, de gênero, de combate à homofobia, de direitos humanos etc. ${ }^{16}$. Como dito mais acima, esse processo institucional fortalece os investimentos na militância e tende a fomentar a "politi-

16 Sobre esse fenômeno no âmbito federal, consultar o livro organizado por Leite Lopes; Heredia (2014). 
zação" de novas questões e de grupos à medida que as condições de atendimento das demandas pelo sistema político apresentam-se favoráveis.

Em sentido oposto, é preciso registrar, por fim, que a saída recente do poder de parte desses grupos após derrotas eleitorais municipais e do impeachment de Dilma Rousseff ${ }^{17}$, no nível federal, tem implicado nova reconfiguração da militância a eles associada - de grande fertilidade como campo de investigação. Como sabido, trata-se de momento de reacomodação tanto na intensidade quanto nas formas dos engajamentos e das militâncias (dos quais o desencanto, a frustração e o desengajamento total ou parcial são o extremo), que tendem a variar de modo proporcional ao investimento que representam aos indivíduos. Da mesma forma, tem-se o enfraquecimento e a perda de visibilidade (talvez, também de legitimidade) relativos de certos movimentos e de "causas" ligadas aos partidos de esquerda que tiveram recuo recentemente.

Esses momentos de maior plasticidade do espaço da militância com frequência são dramáticos para muitos indivíduos e revelam de forma mais explícita, por exemplo, as retribuições esperadas e aquelas obtidas pela ação militante. Eles também favorecem a observação de trânsitos entre diferentes esferas de atividade e a reavaliação da militância (ou das militâncias, em geral), não raro com forte retração do ativismo partidário em benefício daqueles em condições de gerar mais dividendos e menores custos - como o caso do ex-assessor de um parlamentar que, após

17 Em 2001, uma chapa liderada pelo PT venceu as eleições em Aracaju e se manteve até 2012, retornando ao poder em 2017, com um prefeito eleito pelo PCdoB e uma vice do PT. No âmbito estadual, uma chapa liderada pelo PT assumiu o governo em 2007 e se mantém até o presente - desde 2013 sob comando do vice-governador (PMDB) após falecimento do governador Marcelo Déda. Dilma Rousseff (PT) deixou em definitivo a Presidência da República em agosto de 2016, após mais de 13 anos de governo do Partido dos Trabalhadores. Sobre o pouco estudado tema da derrota na política e do abandono da carreira, consultar os trabalhos de Louault (2010) e Florentino (2008). 
fracasso na reeleição, mantém sua participação no partido e em diversos movimentos, porém, tenta apostar no trabalho (mais rentável) de professor em uma faculdade privada como principal atividade. Como se vê, embora pequeno, o Estado de Sergipe oferece campo empírico amplo e de muita riqueza para os interessados em compreender a "participação política" pelo ângulo dos estudos do engajamento e da militância.

\section{Ref erências bibliográficas}

Barthélémy, M. Le militantisme associatif. In: PERRINEAU, P. (dir.). L'engagement politique: déclin ou mutation? Paris: Presses de la Fondation Nationale des Sciences Politiques, 1994.

Carvalho, J. M. de. Religião e política em Sergipe: a participação dos leigos católicos na política partidária. Dissertação (Mestrado em Antropologia) - Programa de Pós-Graduação em Antropologia, Universidade Federal de Sergipe, 2013.

Coradini, O. L. Em nome de quem? Recursos sociais no recrutamento de elites políticas. Rio de Janeiro: Relume-Dumará, 2001.

. Engajamento associativo-sindical e recrutamento de elites políticas. Revista de Sociologia e Política, n. 28, pp. 181-203, jun. 2007a.

. Les participants et les organisateurs du Forum social mondial: la diversité du militantisme. Cultures et Conflits, v. 70, pp. 153-175, 2008.

. Escolarização, militantismo e mecanismos de participação política. In: heredia, B. et. al. (orgs.). Como se fazem eleições no Brasil. Rio de Janeiro: Relume-Dumará, 2002.

Recursos de origem, investimentos e expectativas de retribuição na militância no MST. Espacio Abierto, v. 19, pp. 445-473, 2010.

Dantas, J. I. C. Eleições em Sergipe - 1985-2000. Rio de Janeiro: Tempo Brasileiro, 2002.

Figueiredo, T. C. S. de. Em nome dos professores? Inserção profissional e carreiras políticas. Dissertação (Mestrado em Antropologia) - Programa de Pós-Graduação em Antropologia. Universidade Federal de Sergipe, 2012.

Fillieule, 0. Propositions pour une analyse processuelle de l'engagement individuel: Post Scriptum. Revue Française de Science Politique, vol. 51, no 1-2, pp. 199-215, 2001. 
Florentino, R. Saindo de cena: parlamentares que desistem da disputa eleitoral (1990-2006). Revista de Sociologia e Política, vol.16, n. 30, pp.45-63, 2008.

Gaglietti, M. PT: ambivalências de uma militância. Porto Alegre: Da Casa; Palmarinca, 2003.

Gaxie, D. Le cens caché: inégalités culturelles et ségrégation politique. Paris: Seuil, 1978.

. Rétributions du militantisme et paradoxes de l'action collective. Swiss Political Science Review, 11(1), pp. 157-188, 2005.

Gohn, M. G. M. História dos movimentos e lutas sociais. São Paulo: Loyola, 1995.

Movimentos sociais e redes de mobilizações no Brasil contemporâneo. Petrópolis: Vozes, 2010.

Grill, I. G. "Família”, direito e política no Rio Grande do Sul: os usos do parentesco e dos títulos escolares no exercício do métier. TOMO (UFS), v. 10, pp. 85-111, 2007.

Ion, J. et al. Le militantisme en questions. Grenoble: CRESAL, 1992.

Juhem, P. Entreprendre en politique: de l'extrême gauche au PS. La professionalisation politique des fondateurs de SOS-Racisme. Revue Française de Science Politique, vol. 51, no 1-2, pp. 313-153, 2001.

Lagroye, J. Os processos de politização. Política \& Sociedade (UFSC), v. 16, n. 73, 2017.

Landim, L. "Experiência militante": história das assim chamadas ONGs. In: LANDIM, L. (org.). Ações em sociedade: militância, caridade, assistência etc. Rio de Janeiro: NAU, 1998.

Leite Lopes, J. S.; Heredia, B. A. (org.). Movimentos sociais e esfera pública: o mundo da participação. Rio de Janeiro: CBAE, 2014.

Louault, F. Derrotas eleitorais e carreiras políticas: o caso do PT no Rio Grande do Sul. Revista de Sociologia e Política, 19(40), pp. 233-253, 2011.

Lüchmann, L. H. H. Abordagens teóricas sobre o associativismo e seus efeitos democráticos. Revista Brasileira de Ciências Sociais, v. 29, pp. 159-178, 2014.

Matonti F. \& Poupeau, F. Le capital militant: essai de définition. Actes de la Recherche en Sciences Sociales, n. 154, pp. 5-11, 2004.

Matos, C. M. O. Serviço Social e engajamento: a prática política dos assistentes. Dissertação (Mestrado em Sociologia) - Programa de Pós-Graduação em Sociologia, Universidade Federal de Sergipe, 2010. 
Mische, A. De estudantes a cidadãos: redes de jovens e participação política. Revista Brasileira de Educação, n. 5, 1997.

Nascimento, M. S. A atividade de consultoria ambiental em Sergipe: trajetória, formação e exercício profissional. Trabalho de Conclusão de Curso de Bacharelado em Ciências Sociais. Universidade Federal de Sergipe, 2011.

Neves, P. S. C. A questão negra em Sergipe: visões de militantes e de não-militantes. XXIV Reunião Anual da ANPOCS, Caxambu, 2000.

. Movimentos negros e a questão racial no Brasil contemporâneo: um estudo de caso. In: SANTOS, A. M. dos; GRILL, I. G.; SEIDL, E.; SOUZA, C. (org.). Peças e engrenagens dos jogos políticos no Brasil. São Leopoldo/São Luís: Oikos/EDUFMA, 2012.

Oliveira, W. J. F. de. A arte de resistir às palavras: inserção social, engajamento político e militância múltipla. In: SEIDL, E.; GRILL, I. G. (Org.). As Ciências Sociais e os espaços da política no Brasil. Rio de Janeiro: Fundação Getúlio Vargas, 2013.

Abertura política, militância múltipla e proliferação de protestos públicos em defesa de causas ambientais. Cadernos CERU (USP), v. 20, p. 223239, 2009a.

Elites culturais, militantismo e participação na defesa de causas ambientais. In: Coradini, O. L. (org.). Estudos de grupos dirigentes no Rio Grande do Sul: algumas contribuições recentes. Porto Alegre: UFRGS, 2008a.

. Gênese e redefinições do militantismo ambientalista no Brasil. Dados, v. 51 , p. $751-777,2008 \mathrm{~b}$.

. Os usos da educação no militantismo ambientalista. Pro-Posições, v. 20, n. 2 (59), p. 77-92, 2009b.

. "Paixão pela natureza", atuação profissional e participação na defesa de causas ambientais no Rio Grande do Sul entre 1970 e início dos anos 2000. Tese (Doutorado em Antropologia) - Programa de Pós-graduação em Antropologia Social, Universidade Federal do Rio Grande do Sul, 2005.

Significados e usos sociais da expertise na militância ambientalista. Avá, n.15, 2009c.

Paludo, J. R. Participação de alta intensidade e militantismo dos filiados de base do PT no Brasil. Tese (Doutorado em Sociologia em Política) - Programa de Pós-Graduação em Sociologia Política, Universidade Federal de Santa Catarina, 2017.

Passy, F. Interactions sociales et imbrications des sphères de vie. In: Fillieule, 0 (dir.). Le désengagement militant. Paris: Belin, 2005. 
Perrineau, P. (dir.). L'engagement politique: déclin ou mutation? Paris: Presses de la Fondation Nationale des Sciences Politiques, 1994.

Reis, E. T. dos. A arte da intervenção política: origens sociais, carreiras e destinos de militantes que "lutaram contra a ditadura" no Rio Grande do Sul. In: Coradini, O. L. (org.). Estudos de grupos dirigentes no Rio Grande do Sul: algumas contribuições recentes. Porto Alegre: UFRGS, 2008.

Contestação, engajamento e militantismo: da 'luta contra a ditadura' à diversificação das modalidades de intervenção política no Rio Grande do Sul. Tese de Doutorado. Programa de Pós-Graduação em Ciência Política. Universidade Federal do Rio Grande do Sul, 2007.

; Grill, I. G. Letrados e votados: lógicas cruzadas do engajamento político no Brasil. TOMO (UFS), n. 13, pp. 127-168, 2008.

Sader, E. Quando novos personagens entraram em cena: experiências e lutas dos trabalhadores da grande São Paulo (1970-1980). São Paulo : Paz e Terra, 1988.

Santos, A. S. dos. Movimento Não Pago: emergência e condições de representação no cenário público de Aracaju/SE. Trabalho de Conclusão de Curso de Graduação em Ciências Sociais, Universidade Federal de Sergipe, 2014.

Sawicki, F; Siméant, J. Inventário da sociologia do engajamento militante: nota crítica sobre algumas tendências recentes dos trabalhos franceses. Sociologias, v. 13, n. 28, pp. 200-255, 2011.

Seidl, E. Disposições a militar e lógicas de investimento militante. Pro-Prosições, v. 20, n. 2(59), pp. 21-39, 2009a.

Escolarização e recursos culturais na composição de carreiras militantes. Cadernos CERU (USP), série 2, v. 20, n. 1, p. 155-169, 2009 b.

Engajamento e investimentos militantes: elementos para discussão. In: carrano, P. C.; Fávero, O. (Org.). Narrativas Juvenis: olhares de pesquisas em educação, mídia e ciências sociais. Niterói: EDUFF, p. 55-70, 2014a.

. Notas sobre ativismo juvenil, capital militante e intervenção política. Política \& Sociedade, v. 13, p. 63, 2014b.

; Garcia, A. L. Notas sobre (des)engajamento e militância no Movimento Passe Livre em Florianópolis. Paper apresentado no III Seminário Participação Política e Democracia: o giro político recente no Brasil. Novas formas de envolvimento político em contextos de mudança. Universidade Estadual de Maringá, 2017.

Leandro, H. W. S. Dirigentes políticos em Sergipe: um grupo em mutação? In: Santos, A. M. dos; Grill, I. G.; Seidl, E.; Souza, C. (org.). Peças e 
engrenagens dos jogos políticos no Brasil. São Leopoldo/São Luís: Oikos/ EDUFMA, 2012.

Silva, M. K.; Ruskowski, B de O. Condições e mecanismos do engajamento militante: um modelo de análise. Revista Brasileira de Ciência Política, n. 21, pp.187-226, 2016.

; Oliveira, G. de L. A face oculta(da) dos movimentos sociais: trânsito institucional e intersecção Estado-Movimento - uma análise do movimento de Economia Solidária no Rio Grande do Sul. Sociologias, 13, n. 28, pp. 86-124, 2011.

Sousa, R. S. Filantropia e participação política pela causa do câncer em Sergipe. Dissertação (Mestrado em Sociologia) - Programa de Pós-Graduação em Sociologia, Universidade Federal de Sergipe, 2010.

Souza, M. E. S. de. Militância negra em Sergipe: investimentos e estratégias individuais. Monografia de Conclusão de Curso de Bacharelado em Ciências Sociais. Universidade Federal de Sergipe, 2009.

. Movimento negro em Sergipe e política institucional: uma análise a partir de carreiras de militantes negros. Dissertação (Mestrado em Sociologia) - Programa de Pós-Graduação em Sociologia, Universidade Federal de Sergipe, 2012.

. Trajetórias individuais, redes sociais e mediação: elementos para o estudo da emergência de lideranças na defesa da "causa negra" em Sergipe. In: Santos, A. M. dos; Grill, I. G.; Seidl, E.; Souza, C. (org.). Peças e engrenagens dos jogos políticos no Brasil. São Leopoldo/São Luís: Oikos/EDUFMA, 2012.

Steckel, D. de 0. G. Veredas e atalhos: recrutamento e seleção de elites políticas em Sergipe. Dissertação (Mestrado em Sociologia) - Programa de Pós-Graduação em Sociologia, Universidade Federal de Sergipe, 2007.

Recebido em 30/01/2018

Aprovado em 04/02/2018 